\title{
Emile Zola, La Fabrique des Rougon-Macquart
}

\section{Maria Emanuela Raffi}

\section{(2) OpenEdition}

\section{Journals}

\section{Edizione digitale}

URL: http://journals.openedition.org/studifrancesi/7676

DOI: 10.4000/studifrancesi.7676

ISSN: 2427-5856

\section{Editore}

Rosenberg \& Sellier

\section{Edizione cartacea}

Data di pubblicazione: 1 décembre 2009

Paginazione: 657

ISSN: 0039-2944

\section{Notizia bibliografica digitale}

Maria Emanuela Raffi, «Emile Zola, La Fabrique des Rougon-Macquart», Studi Francesi [Online], 159 (LIII ) III) | 2009, online dal 30 novembre 2015, consultato il 09 janvier 2021. URL: http:// journals.openedition.org/studifrancesi/7676 ; DOI: https://doi.org/10.4000/studifrancesi.7676

Questo documento è stato generato automaticamente il 9 janvier 2021.

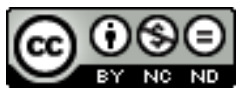

Studi Francesi è distribuita con Licenza Creative Commons Attribuzione - Non commerciale - Non opere derivate 4.0 Internazionale. 


\title{
Emile Zola, La Fabrique des Rougon- Macquart
}

\author{
Maria Emanuela Raffi
}

\section{NOTIZIA}

EMILE ZOLA, La Fabrique des Rougon-Macquart, édition des dossiers préparatoires. Publiés par Colette BECKER avec la collaboration de Véronique LAVIELLE, vol. IV, Paris, Champion, 2009, pp. 1239.

1 Si segnala la pubblicazione dell'imponente IV volume dei «Dossiers préparatoires» di Zola, che comprende due dossiers relativi al romanzo Au bonheur des dames (NAF $10277 \mathrm{e}$ NAF 10278) e uno relativo a La Joie de vivre (NAF 10311). Nel saggio introduttivo, Le -corps à corps avec les mots à propos des brouillons de Zola, Colette Becker mostra la «dynamique de l'écriture» di Zola, che, attraverso i brouillons, rivela il costruirsi dei romanzi anche attraverso cancellazioni e correzioni. In particolare, vengono presi in considerazione anche i frammenti scritti sul verso dei dossiers, non considerati nelle edizioni precedenti, che Colette Becker classifica in tre tipi: «A - morceaux de comptes rendus de pièces de théâtre ou d'articles» o parti di lettere, che possono essere datati e quindi informano sulle tappe della genesi del testo scritto sulla parte anteriore del foglio, «B quelques lignes de pièces de théâtre» soprattutto tratte da préfaces, «C.- [...] morceaux de brouillons de romans» ed è questo il caso più frequente. Oltre all'interessante interazione fra recto e verso dei fogli, la curatrice mette in rilievo anche il contributo fornito, per la comprensione della genesi dei testi, dallo studio dei vari tipi di correzioni introdotte dall'autore. 